INTERNATIONAL HIGHER EDUCATION - NUMBER 66 WINTER 2012 Pages 29-30.

Why the Argentine Private University Sector Continues to Lag

Marcelo Rabossi

Marcelo Rabossi is assistant professor at the School of Government, Torcuato Di Tella University, Buenos Aires, Argentina. E-mail: mrabossi@utdt.edu.

IHE devotes a column in each issue to a contribution from PROPHE, the Program for Research on Private Higher Education, headquartered at the University at Albany. See http:/ / www.albany.edu/.

In Latin America, the private sector holds roughly half of all higher education enrollment. In Argentina it holds a fifth. No other large country in Latin America is nearly as low in the private share. Why does Argentina continue to be so different and will this change?

\title{
EARLY STAGES
}

The private university sector in Argentina began late, in comparison to other systems in Latin America. Attempts to challenge the public monopoly, particularly during the first half of the 20th century, faced strong state opposition. Only after intense compromises with the executive power, would Argentina open its first private university (in 1959). At the time, the large majority of Latin American countries had already established a private sector, and only 3 of the 20 republics would not have done so by 1962. After Argentina's public monopoly of more than 130 years was broken, the private market began a process of enrollment expansion. By the end of the 1960s, it captured almost one of every five university students. 
The expansion of the private market was in some instances, as in Mexico, a response to defend the status of elites in higher education as the public university absorbed more and more students of modest socioeconomic background. In Argentina, however, the public sector was not only the main absorber of new students but remained committed to keeping its position at the top of the hierarchical pyramid. The private market was never thought as a complementary tool to lessen the paramount stature of the national institution. In comparison to the region overall, private options have never found fertile ground to expand to a large share of enrollment.

Argentina's historical emphasis on the public university has held, even during periods of fiscal crises. Though it may appear economically perverse, the nature of the Argentine political system meant that during the 1980s, while an exhausted state was begging for funds, the doors of the national university were opened for all secondary school graduates. Policy in effect since 1973, allowing no new private universities, was not lifted until 1989. Thus, Argentina became one of the few Latin American countries to witness a decline in the private share of enrollment. In sum, the private sector in Argentina was tolerated but not part of a systemic design.

\section{A New Opportunity for Private Alternatives}

However, the early 1990s, amid neoliberal political/economic policy, brought another chance for private expansion. With the entry of 23 new institutions between 1989 and 1995, for the first time private universities outnumbered public ones (48 to 40). These newcomers added heterogeneity in a system dominated in enrollment by the public side ( $86 \%$ in 1995). But, quickly, the opening of the 
National Accreditation Agency (CONEAU) in 1996 was a new barrier to private expansion. The agency was immediately strict in its requirements, rejecting almost 9 of every 10 entry applications. For example, looking at the last 10 years of available official data (2000-2009), only 12 private universities were allowed to enter the market, and only 3 since 2005. Within this panorama, by the end of 2009, 60 private institutions are found to be enrolling only 20 percent of all university students-in other words, a percentage not dissimilar to the one reached at the end of the 1960s (18\%).

A significant fact during the period (2000-2009) was that new public enrollees remained stable (at 290,000), while private freshmen grew (from 62,000 to 97,000$)$. Thus, 25 percent of all new students in 2009 chose the nonpublic option. Consequently, private enrollment increased by 6 percentage points (from 14 to 20\%). Probably the increase in the purchasing power of salaries during the last five or six years helps explain this private growth. Also, we can speculate that an increasing number of families perceive that from an academic and organizational perspective the private sector is less internally politicized or conflicted and thus enhances the ease of completing degrees. Such a perspective has over the years contributed to private growth elsewhere in the region.

However, given Argentina's statist tradition and political culture, the public sector reacted by establishing new universities. The public side has begun to widen its academic offerings again, by opening several branches and new institutions (some in places unattractive for private investors). There have been 9 new public institutions since 2005. Evidently, the state is still not disposed to give up its role of main-demand absorber. 


\section{More RoOm for Private Alternatives?}

Even as the private sector is now enrolling one out of every four new students, its ability to increase this proportion remains unclear. Argentina does not offer the friendliest environment for private undertakings. Most public policies are far from fostering private alternatives. The open admission that mainly rules the public sector since 1983 hardly favors the development of a larger private market. Unlike some regional counterparts (though not others), Argentina also maintains a policy of no tuition for public higher education at the undergraduate level. Also, there are no available public-subsided loans for students who chose a private institution. Loans are not prevalent for the public sector either, but it is only the private sector that charges major fees. From the supply side, public policies are not friendly for new private investors. While the opening of new public universities does not need to get the National Accreditation Agency's approval, nonpublic undertakings are strictly controlled by the agency. Such a situation may arise when the state trusts its national institutions more than the private counterparts.

In sum, Argentina has debatable but strong dual barriers to private higher education growth: demanding public-policy regulations on the private sector and expansive or even lax policy within the public side, particularly concerning the opening of new institutions. Thus, no major conditions are seen as an expectation for a private boom in Argentina that would bring the country toward the regional private higher education share. 